\title{
How Does Cultural Intelligence Influence the Relationships between Potential and Realized Absorptive Capacity and Innovativeness? Evidence from Poland
}

By

Ismail Gölgeci $^{1}$, Justyna Swiatowiec-Szczepanska ${ }^{2}$ and Konrad Raczkowski ${ }^{3}$

${ }^{1}$ Lecturer in Marketing, University of East Anglia, Norwich Research Park, Norwich, Norfolk, NR4 7TJ, UK. Tel. +44 7548251352 e-mail: i.golgeci@uea.ac.uk

${ }^{2}$ Associate Professor, Poznan University of Economics, al. Niepodległości 10, 319A, 61-875 Poznań, Poland. Tel. +48 618569436 e-mail: justyna.swiatowiecszczepanska@ue.poznan.pl

${ }^{3}$ Associate Professor, University of Social Sciences, ul. Chodakowska 19/31, 03-815, Warsaw, Poland. e-mail: raczkowski.konrad@gmail.com

Forthcoming in Technology Analysis \& Strategic Management

DOI: $\underline{\text { http://dx.doi.org/10.1080/09537325.2016.1245858 }}$ 


\begin{abstract}
Cultural intelligence underpins the interaction between firms and their cultural environments as the domain of external sources that are explored and utilized for innovation through absorptive capacity. This research seeks to answer the question of if and how cultural intelligence moderates the links between innovativeness and potential and realized absorptive capacity. We test our hypotheses based on data from 215 firms operating in Poland. We demonstrate that cultural intelligence strengthens the linkage between potential absorptive capacity and innovativeness that highlights cultural intelligence as an important enabler of exploring new and diverse external knowledge sources. We discuss cultural intelligence concept in relation to strategic management and reveal its contingent role in innovativeness.
\end{abstract}

Key Words: Cultural intelligence, Innovativeness, Absorptive capacity, Poland 


\section{Introduction}

The power of brands, innovations, and efficient distribution networks of multinational enterprises (MNEs) from developed markets create formidable performance and survival challenges to emerging market firms (Buckley, 2009). Facing these challenges requires developing new products, services, and/or management practices through innovativeness. Thus, understanding the enablers of innovativeness is essential and is particularly relevant to many EMFs in order to transcend mediocre practices and ordinary products. One particular key concept studied repeatedly in relation to firm innovativeness has been absorptive capacity (ACAP) (Cepeda - Carrion, Cegarra - Navarro, \& Jimenez - Jimenez, 2012; Chang et al., 2013; Cohen \& Levinthal, 1990). These studies have established both potential absorptive capacity (PACAP) and realized absorptive capacity (RACAP) as key enablers of firm innovativeness.

Despite extensive research on the enablers of firm innovativeness (e.g., Cepeda - Carrion et al., 2012; Chang et al., 2013), less attention has been paid to the cultural aspects regarding firm innovativeness, especially in emerging market contexts. The role of the socio-cultural factors in EMFs' innovative capabilities and behavior has been largely overlooked in the literature (Van Everdingen \& Waarts, 2003) in spite of largely recognized pervasive influence of culture on firm behavior and structure (Taras, Kirkman, \& Steel, 2010). In particular, the important concept of organizational cultural intelligence (CQ) (Earley \& Ang, 2003) has not been sufficiently brought into strategy research examining innovation and performance. CQ is a key dynamic capability to manage in culture (Moon, 2010). Explaining the interactions between the cultural settings and socioeconomic entities embedded in these settings, CQ goes beyond the extensively researched notion of cultural values when studying management in relation to culture (Taras et al., 2010). However, the role CQ plays in innovation, as a key premise of strategic management, remains as a crucial void to be filled.

The primary purpose of this research is to examine the moderating role of cultural intelligence in the relationships between potential and realized absorptive capacity and innovativeness. We view 
CQ as a dynamic capability that enables firms to navigate smoothly and manage effectively in various cultural settings (Moon, 2010) and investigate how it shapes the linkages between the firm's key capabilities concerning innovation. In doing so, we examine the joint role that PACAP, RACAP, and CQ play in the extent of development and exercise of Polish firms' innovative capabilities.

With this research, we aim to make two distinct contributions strategic management research. First, we discuss the relevance of CQ to innovation embedded in cultural environments. Culture has extensively been studied in organization studies (e.g.,Sultan \& van de Bunt-Kokhuis, 2012) and crosscultural research (e.g.,Taras et al., 2010). However, CQ, in particular, has not been sufficiently examined in relation to innovation strategy. Our first contribution fills this gap through an initial attempt to explore CQ within the domain of innovation strategy.

Second, we empirically probe into the role CQ play concerning the influence of PACAP and RACAP on innovativeness. Despite business fields' relative ignorance, behavioral dimensions of intercultural encounters appear to matter for the key drivers of innovation. We specifically show that the control of cultural cognition and manifestation of intercultural capabilities are intertwined with the explorative facet of ACAP. This contribution helps advance the research on dynamic capabilities by exploring the boundary conditions and contingencies of innovation related dynamic capabilities (Barreto, 2010). In particular, we illustrate that PACAP's role in innovativeness cannot be fully understood without accounting for dynamic capabilities of intercultural acumen and behaviors manifested at the interface between the diverse domains of knowledge exploration and innovation.

\section{Theoretical overview and hypotheses}

\subsection{Innovativeness and absorptive capacity}

\subsubsection{Innovativeness}

Firm innovativeness refers to organization's capacity and willingness to innovate — to create or adopt innovations and implement them successfully (Tuominen, Rajala, \& Möller, 2004). Innovativeness is distinct from yet embedded in its cultural settings (Azadegan \& Dooley, 2010; Golgeci \& Ponomarov, 
2013). Innovativeness is an important organizational capability for competitive advantage in vigorous and culturally diverse environments of emerging markets (Yu et al., 2013). Thus, despite being underresearched in emerging markets context, innovativeness is not alien to EMFs and may be leveraged for EMFs' competitive advantage. In this research, innovativeness is considered in the context of emerging markets, specifically Poland. Although there has been recent efforts and incremental improvements to move Poland's economy toward more of an innovation-driven economy, Polish firms typically remain as efficiency-driven firms partially due to institutional and cultural factors (Schwab, Sala-i-Martin, \& Brende, 2013).

\subsubsection{Potential and realized absorptive capacity}

Absorptive capacity (ACAP) refers to a set of organizational routines and processes by which firms acquire, assimilate, transform, and exploit knowledge to produce a dynamic organizational capability (Zahra \& George, 2002). It emerges from the actions and interactions of individual, organizational, and interorganizational entities (Volberda, Foss, \& Lyles, 2009). It sits at the epicenter of knowledge capacities of the firm (Lichtenthaler \& Lichtenthaler, 2009). ACAP is underlain by distinct learning routines of identifying, assimilating, and exploiting knowledge that reinforce, complement, or refocus the firm's knowledge base (Lane, Koka, \& Pathak, 2006).

ACAP comprises two complementary and interconnected constructs that underline the understanding of the concept at two distinct major stages. Those complementary and interconnected constructs are potential ACAP (PACAP) and realized ACAP (RACAP) (Chang et al., 2013; LealRodríguez et al., 2014), even though their demarcation may not be in absolute terms (Todorova \& Durisin, 2007). The interface between PACAP and RACAP is a behaviorally intricate domain of processes (Volberda et al., 2009) that transform and apply today's knowledge for tomorrow's problems. Dividing ACAP into the dimensions of PACAP and RACAP resides in the underlying principle that capabilities can be viewed as potentials that are more meaningful for their beholders when they are realized (Zahra \& George, 2002). Having a capability as a potential is a needed 
precondition, but not a sole determinant, of realizing that potential to meet ends, which casts PACAP and RACAP as complementary yet distinct characteristics of ACAP.

PACAP consists of two capabilities of acquisition, an ability to locate, identify, value and acquire relevant external knowledge and assimilation, an ability that allows analyzing, processing, interpreting, and understanding the information obtained from exogenous sources (Zahra \& George, 2002). PACAP denotes a capacity to evaluate and acquire external knowledge (Leal-Rodríguez et al., 2014). The evaluation and acquisition of external knowledge are contingent upon a pivotal step of recognition of value (Todorova \& Durisin, 2007). RACAP also consists of two capabilities of transformation, an ability to develop and refine the routines that enable combining existing and new knowledge (Zahra \& George, 2002) and exploitation, an ability to refine, extend, and leverage existing competencies or to create new ones by incorporating acquired and transformed knowledge (Cohen \& Levinthal, 1990; Zahra \& George, 2002). PACAP and RACAP are might draw on different structures, objectives, and strategies (Leal-Rodríguez et al., 2014). We analyze these two concepts separately.

\subsubsection{Potential and realized absorptive capacity as enablers of innovativeness}

The strong positive relationship between the two distinct yet complementary dimensions of ACAP (Zahra \& George, 2002) has been consistently confirmed (Cepeda - Carrion et al., 2012; Chang et al., 2013; Leal-Rodríguez et al., 2014). Firm innovativeness typically involves constant influx of new ideas, knowledge, and practices (Capaldo, 2007; Gölgeci \& Ponomarov, 2015). Ability to acquire and exploit external knowledge effectively is pivotal for developing, deploying, and utilizing various innovative capabilities (Cohen \& Levinthal, 1990). PACAP and RACAP function as enablers of ability to turning knowledge into new products, services, or processes (Leal-Rodríguez et al., 2014). PACAP and RACAP represent fundamental underlying mechanisms for organizational learning, which leads to innovativeness (Yu et al., 2013). In particular, PACAP can enable innovativeness by sensing and seizing relevant and creative external knowledge. Likewise, RACAP can enable processing and digestion of external knowledge and turn it into direct inputs for product, service, 
process, and management innovations. Though these capabilities are complementary, acquisition and assimilation of external knowledge do not guarantee its effective leverage for innovativeness, and firms can be high-caliber in transformation and exploitation while being mediocre in acquisition and assimilation (Leal-Rodríguez et al., 2014).

H1: Potential absorptive capacity has a positive impact on innovativeness.

H2: Realized absorptive capacity has a positive impact on innovativeness.

\subsection{Cultural intelligence}

\subsubsection{Cultural intelligence and its relevance to strategic management}

Cultural intelligence $(C Q)$ is defined as the capability to observe, interpret, and act upon unfamiliar and ambiguous social and cultural cues, and function effectively in situations characterized by cultural diversity and novelty (Ang \& Inkpen, 2008; Shapiro, Ozanne, \& Saatcioglu, 2007). CQ may be viewed as a higher-order dynamic capability operant on ordinary cultural capabilities (Moon, 2010). Like most dynamic capabilities, CQ is developed and practiced by individuals and is aggregated into firm level through behavioral and structural means to be leveraged as a response to external demands (Ang \& Inkpen, 2008; Moon, 2010). In this vein, CQ is a relational concept that is especially relevant when interacting with people and organizations of different cultures (Magnusson et al., 2013). It is a strategic imperative for businesses in light of the perseverance of varying cultural norms and values and their variation both within and across national boundaries (Ang \& Inkpen, 2008). It can foster successful communications with culturally diverse potential partners and enable uncovering novel insights and information. For example, CQ was found to be positively related to the effectiveness in intercultural negotiations (Imai \& Gelfand, 2010) that is essential to obtaining best relational rents.

The effectiveness of behaviors, skills, and values in one context may not transfer across other contexts (Earley \& Ang, 2003). Social entities (individuals, groups, and organizations) need to learn and exercise the artifacts and tools and to participate in these practices that require particular socialcognitive skills of social learning and communication associated with the relevant culture to succeed 
in intercultural interactions (Ang \& Inkpen, 2008). CQ is a key cultural construct that is particularly relevant to management in relational settings informed and influenced by culture (Ang \& Inkpen, 2008; Imai \& Gelfand, 2010).

The necessity of CQ is the natural outcome of globalization and increased interaction and interdependence among culturally different social and political entities (Earley \& Ang, 2003). In the world of cultural, institutional, economical, and societal diversity and dynamism, greater complexity and differentiation, increasing rigidities in values, and intolerance and insensitivities against differences, managing relationships among interacting parties are becoming increasingly challenging (Moon, 2010; Shapiro et al., 2007).

Contemporary definitions and conceptualizations of CQ highlight a multifaceted and sophisticated concept that is manifested between different levels and within temporal and spatial contexts (Ang, Van Dyne, \& Koh, 2006; Moon, 2010). Such a complicated concept with interdependent yet distinct attributes requires a multidimensional explanation to better reflect its properties. Accordingly, CQ is conceptualized as encompassing four distinct dimensions to mirror the contemporary views of intelligence as a complex, multifactor, multilevel attribute (Ang \& Inkpen, 2008; Molinsky, 2007). These dimensions are metacognitive (knowledge and control of cognition, planning, monitoring, and revision of mental models); cognitive (knowledge structures, alertness, pattern recognition, and self-awareness); motivational (learning, efficacy, persistence, goals, enrichment, and values); and behavioral (collection of practices, customs, and habits) (Ang et al., 2007) intelligence.

Though they collectively represent CQ, these four capabilities denote different attributes and may have different influences (Magnusson et al., 2013). First, Ang et al. (2007) argue that metacognition, cognition, and motivation are mental capabilities that reside within the mind, while explicit actions are behavioral capabilities. Second, both metacognitive and cognitive intelligence are primarily related to cognition, though motivational and behavioral intelligence are relatively closer to 
the manifestation of CQ. Third, metacognition and cognition differ from each other in that metacognition denotes the control of cognition, cultural judgment, and decision making, while cognition denotes knowledge structures within the mind (Ang et al., 2006; Ang et al., 2007). Likewise, while motivational intelligence is a step closer to overt action due to its relevance to interactional adjustment and well-being (Ang et al., 2007), it represents magnitude and direction of a cultural entity's drive to exercise CQ (Ang et al., 2006), and thus is different from behavioral intelligence.

CQ can as well be utilized to respond to and navigate through bounding cultural forces (Moon, 2010). It enables setting culturally suitable goals and implementing innovations more effectively by responding to cultural differences, ambiguities, and complexities (Elenkov \& Manev, 2009; Moon, 2010). We argue that one of the means to leverage CQ resides in its potential facilitating role in translating PACAP and RACAP into increased innovativeness.

\subsubsection{The moderating role of cultural intelligence}

To identify and shape exogenous opportunities, firms must constantly scan, search, and explore technologies and markets on a global scale (Teece, 2009). A relevant capability for such pursuits, CQ could be viewed as an antidote for the challenges of cultural differences that hinder knowledge exploration and transfer (Fabrizi, Guarini, \& Meliciani, 2016). Nonetheless, because CQ is a multidimensional construct with related yet independent dimensions (Ang et al., 2006; Ang et al., 2007; Magnusson et al., 2013), its dimensions may play different moderating roles in translating PACAP and RACAP into innovativeness. In particular, since CQ is an explorative capability (Moon, 2010), we expect a stronger positive moderation by CQ on the link between PACAP and innovativeness than the link between RACAP and innovativeness. Besides exploiting existing external knowledge bases in greater depth, firms need to extend their scope by exploring new external knowledge sources (Borgatti \& Foster, 2003; Dyer \& Singh, 1998); and the extant theory signals that CQ could be a proper capability to do so (Elenkov \& Manev, 2009; Moon, 2010). In particular, the central role of CQ in effective initiation and management of intercultural interactions (Earley \& Ang, 
2003) could serve as an underlying mechanism for exploring valuable knowledge from such sources of diverse cultural backgrounds.

PACAP and the four dimensions of CQ is likely to act better jointly than alone (Teece, 2009). Because cognitive capabilities are inextricably intertwined with knowledge absorption and learning, we argue that higher degree of control of knowledge (metacognitive intelligence) and knowledge structures (cognitive intelligence) can result in higher degrees of knowledge acquisition and assimilation for innovativeness. Metacognitive intelligence enhances contextualized thinking that is characterized by high degrees of sensitivity to the external environment (Klafehn, Banerjee, \& Chiu, 2009), which is essential for acquiring external knowledge. Likewise, because intrinsic interest in other cultures and proper behavior in such contexts is likely to result in positive creative knowledge outcomes (Ang et al., 2007), it is possible that motivational and behavioral intelligence can function as catalyzing mechanisms to PACAP in its impact on innovativeness. In particular, motivational intelligence provides a control of affect, cognition, and behavior that facilitates accomplishing knowledge exploration related goals (Chen, Liu, \& Portnoy, 2012). Firms that are able and willing to direct and sustain energy on adapting to and functioning appropriately in new and diverse cultural situations are often in a better position to gain unique insights from their encounters (Molinsky, 2007). Furthermore, realizing CQ through behavioral intelligence can have spillover effects on acquiring and assimilating innovative knowledge from external sources, because firms typically share their novel ideas with actors who are better at communicating with them (Capaldo, 2007). Accordingly, we expect a positive moderation of the four dimension of CQ on the link between PACAP and innovativeness, even though these effects could be manifested differently.

H3: Metacognitive (a), cognitive (b), motivational (c), and behavioral (d) intelligence dimensions of cultural intelligence positively moderate the link between potential absorptive capacity and innovativeness. 
The key difference between PACAP and RACAP is that while PACAP relates closer to the exploration of new external knowledge opportunities, RACAP relates closer to the exploitation of what is already at hand (Zahra \& George, 2002). It has been revealed that cognitive capabilities are particularly relevant for exploitation (Renko, 2008). Likewise, since metacognitive intelligence encapsulates the planning for how to use one's knowledge (Ang et al., 2007), it can strengthen the role of RACAP in innovativeness. Furthermore, motivational and behavioral intelligence are actionoriented dimensions of CQ (Magnusson et al., 2013), which could tie well with activity-intensive capability of RACAP in fostering innovativeness. In a similar vein, CQ boosts internal cohesion within firms (Ang et al., 2007), which is likely to facilitate smoother firmwide diffusion of acquired knowledge. Collective organizational CQ can be reflected in managers' increased identification with their firm and in ensuing effectiveness of RACAP for innovativeness. Thus, we posit that transformation and exploitation of knowledge can result in higher degree of innovativeness if they are coupled with four dimensions of CQ.

H4: Metacognitive (a), cognitive (b), motivational (c), and behavioral (d) intelligence dimensions of cultural intelligence positively moderate the link between realized absorptive capacity and innovativeness.

Figure 1 presents the research hypotheses of the study.

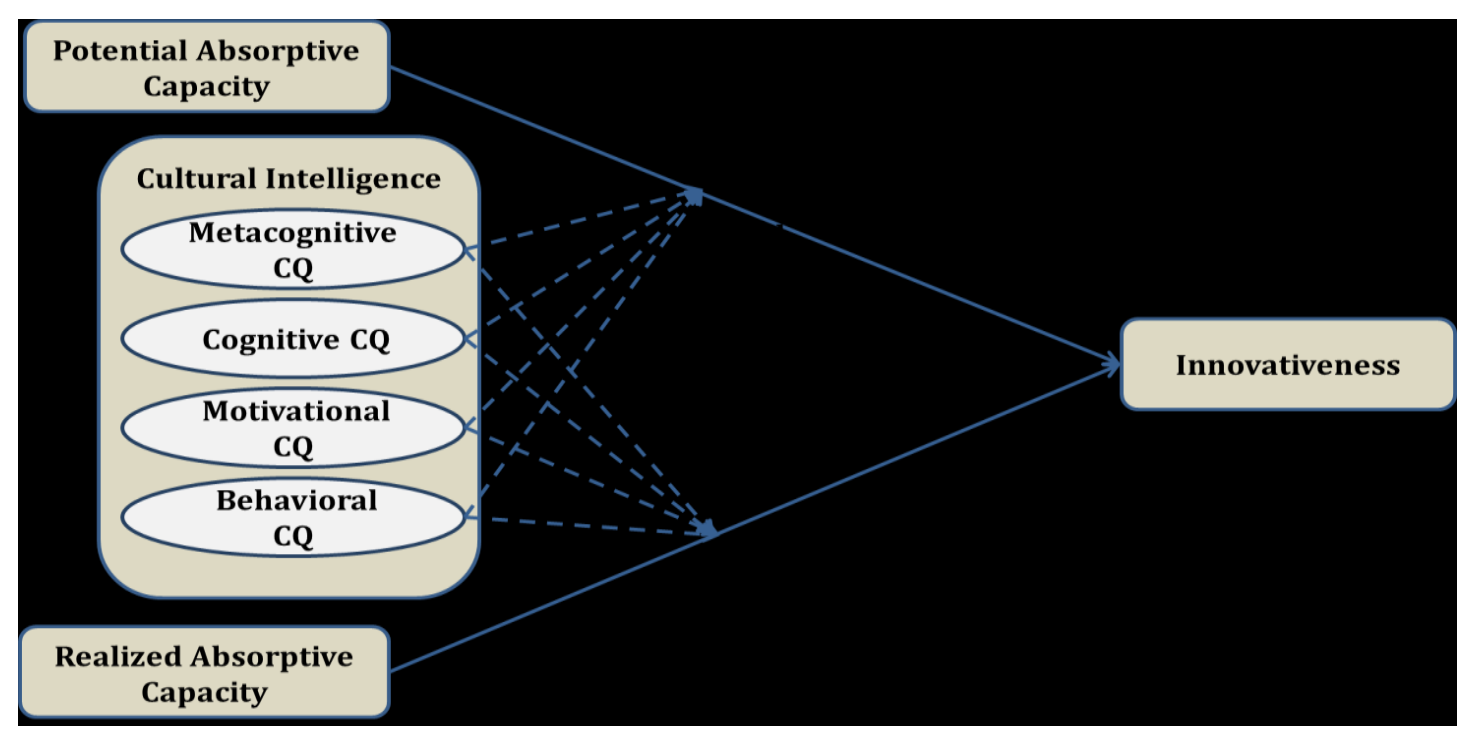

Figure 1. The research model 


\section{Research method}

\subsection{Poland's cultural and economic context}

Poland is a typical example of an emerging economy in the Central Europe and since 2004, it has been the most populous and largest post-communist member of the European Union. However, current Poland's economic and sociocultural structure reflects its legacy of rich history and its location. A rich and dynamic history, constant change in its borders, and a location at the intersection of various interacting cultural streams (particularly those of Germanic and Slavic) led Poland to become a relatively diverse country in terms of its culture.

Cross-regional cultural differences within Poland amplify the relevance of CQ even at the country level. East-Central provinces are higher in harmony, intellectual autonomy, and egalitarianism and lower in mastery and hierarchy than more Eastern provinces (Schwartz, 2006). Besides, East-Central provinces have stronger historical and trade links to Western Europe, were less penetrated by totalitarian communist rule, and threw it off earlier (Schwartz, 2006). Likewise, the Polish culture houses several cultural contradictions. For example, although highly individualistic, the Polish are hierarchical (Hofstede, 1983). Such combinations create cultural tensions or ambiguities in this culture that could be addressed via CQ (Earley \& Ang, 2003).

Though not fully innovation driven, Poland demonstrates sufficient technological readiness (Schwab et al., 2013). However, despite its relatively stable economy and substantial education level of its citizens (Schwab et al., 2013), many social challenges remain to be an important barrier for Polish firms to innovate. This has resulted relatively in low R\&D intensity and innovativeness of Polish firms in EU. Poland was ranked $25^{\text {th }}$ in Innovation Union Scoreboard 2013, the innovativeness report of all EU member states prepared by the European Commission. Subsequently, relatively rich cultural background and changing the innovative landscape of Poland offers a proper empirical context to fulfill the purpose of this research.

\subsection{Data collection}


Data for the quantitative research were collected on a sample of firms from all major regions of Poland. The basic selection criterion for the firm participation in the research was an industry field that entails higher degrees of innovation. The focus was on firms in the following high-tech industries: telecommunications $(7.5 \%)$ the internet and value-added services $(14.0 \%)$, software and system integration (15.8\%), computer electronics (30.7\%), biotechnology and pharmaceuticals (13.9\%), and others (18.1\%). The other important criterion was firm's international activity. We obtained a list of 9788 firms located across different provinces of Poland from BISNODE database and conducted the survey on-line. However, after eliminating the firms that do not fit the selection criteria and omitting bad contacts due to e-mail delivery failure, we reduced final sample to 2050 firms. The resulting data set consists of 215 firms from 15 Polish provinces representing participations from all but one region and a $10.5 \%$ response rate. The median number of employees in this final sample was between 50 and 249. On average these firms have been operating for 13 years. The large share $(62.8 \%)$ of the sample firms was Polish-owned, followed by majority foreign-owned (27.0\%) and Polish firms with foreign partnerships $(10.3 \%)$.

We paid necessary attention to design our survey simple, lucid, concise, and navigable so that participants could complete them conveniently without confusion or fatigue (Dillman, 2007). The items/scale used in the study drew on established research. When translating items into Polish, linguistic, conceptual, and technical issues were addressed (Mckenna et al., 2013) by adopting forward-backward translation by a panel of independent bilinguals and cross-comparing translations until reaching consensus on most proper translations of the items.

\subsection{Measurements}

We adopted all items for measuring variables of interest from existing literature and applied 7-point Likert-type scale. The appendix shows detailed Cronbach's as, factor loadings, and related prior studies we used when developing questions items for the major variables used in the study. We 
conducted both exploratory and confirmatory factor analyses. Loading patterns in both analyses clearly differentiate across variables and factor solution consistent with our hypotheses.

We measured innovativeness by five items adapted from the instruments developed by Golgeci and Ponomarov (2013). The variable highlights the extent to which the company creates or adopts innovations and implements them successfully. The final measure of innovativeness is the average of response to five items with high validity and reliability (Cronbach's $\alpha=0.85$, convergent factor loadings from 0.72 to 0.87 ).

We adopted the items by Jansen, Van Den Bosch, and Volberda (2005) for measuring potential and realized absorptive capacity. We used six items to measure potential absorptive capacity (PACAP) (Cronbach's $\alpha=0.90$, convergent factor loadings from 0.70 to 0.85 ) and five items for realized absorptive capacity (RACAP) (Cronbach's $\alpha=0.90$, convergent factor loadings from 0.70 to $0.80)$.

We complied with the existing literature that views cultural intelligence (CQ) as a composite factor with four distinct dimensions: metacognitive; cognitive, motivational and behavioral intelligence (Ang et al., 2007). Given the breadth of the CQ construct, covering 20 items, we used exploratory factor analysis [EFA] to explore and confirm its underlying dimensions and retain the most effective items. Based on EFA results and convergent validity we chose 13 original CQ questions that captured and confirmed all four dimensions as proposed in earlier studies. The variables indicate satisfactory reliability and validity with Cronbach's $\alpha$ from 0.77 to 0.87 .

We tested the construct validity of the indicators of latent variables using confirmatory factor analysis [CFA] (see Appendix). All items loaded significantly on their expected constructs $(p<0.01)$. The fit indexes show that the overall model provides satisfactory fit to the data $\left(\chi^{2} / \mathrm{df}=1.98\right.$, $\mathrm{RMSEA}=0.068, \mathrm{CFI}=0.95)$. From an examination of the results, shown in the Appendix we can state that all of the constructs are reliable. Their values for both the Cronbach $\alpha$ coefficient are greater than the value of 0.7 and the factor loadings exceed the commonly accepted threshold of 0.6 for each 
variable (Bagozzi \& Yi, 1988). Furthermore, the construct reliability [CR] of all construct exceeds the 0.70 benchmark (Nunnally \& Bernstein, 1994), and all average variance extracted [AVE] are greater than 0.50 (Chin, 2003). These measures demonstrate adequate convergent validity and reliability (Fornell \& Larcker, 1981).

We evaluated the discriminant validity by employing several tests. First, we ran a series of chi-square tests for all constructs in pairs (with correlation $>0.4$; see table 1) to determine whether the unconstrained model is significantly better than the constrained model (Hair et al., 2010). All the chisquare differences besides one are highly significant, indicating discriminant validity (e.g. cognitive intelligence versus motivational intelligence: $\left.\Delta \chi^{2}(1)=18.81, p=0.000\right)$. However in the case PACAP versus RACAP the chi-square differences is non-significant $(\Delta \chi 2(1)=1.47, p=0.226)$. Accordingly, as an additional step to asses discriminant validity, we conducted a test of shared variance between the pairs of latent constructs as suggested by Fornell and Larcker (1981). The average variance extracted for each pair of constructs is greater than their squared correlations. Furthermore, none of the questions in the factor analyses has loadings in excess of 0.40 on more than one factor and the correlations of individual factors do not exceed the alpha coefficients, which lend support to discriminant validity according to Crocker and Algina (1986). These results suggest that discriminant validity is not a serious concern. As we intend to examine moderating effects of CQ to both dimensions of ACAP, we decided to build two separately models with PACAP and RACAP.

\subsection{Analysis}

We analyzed the data using hierarchical moderated multiple regression, which is particularly appropriate for testing of moderation effects (Carte \& Russell, 2003) proposed in Hypotheses 3 and 4. The empirical models include PACAP (or RACAP), CQ variables and the interaction between PACAP (or RACAP) and CQ variables as explanatory variables. We also include other control variables of firm size, firm age, industry, and ownership.

The model tested with PACAP was: 
$I N N O V=\beta_{0}+\beta_{1} P A C A P+\beta_{2} M C Q+\beta_{3} C C Q+\beta_{4} M O C Q+\beta_{5} B C Q+\beta_{6} P A C A P x M C Q+\beta_{7} P A C A P x C C Q+$ $\beta_{8} P A C A P x M O C Q+\beta_{9} P A C A P x B C Q+\beta_{10}($ SIZE $)+\beta_{11}(I N D U S T R Y)+\beta_{12}(A G E)+\beta_{13}(O W N)$

The model tested with RACAP was:

$I N N O V=\beta_{14}+\beta_{15} R A C A P+\beta_{16} M C Q+\beta_{17} C C Q+\beta_{18} M O C Q+\beta_{19} B C Q+\beta_{20} R A C A P x M C Q+\beta_{21} R A C A P x C C Q+$ $\beta_{2} R A C A P x M O C Q+\beta_{23} R A C A P x B C Q+\beta_{24}(S I Z E)+\beta_{25}(I N D U S T R Y)+\beta_{12}(A G E)+\beta_{26}(O W N)$

\section{Results}

Table 1 reports means, standard deviation, and Pearson's correlation coefficients for all variables used in this study. As can be seen, some high correlations exist among certain variables. For example, the correlation between PACAP and RACAP $(r=0.64)$ is high. Because of relatively high correlation between PACAP and RACAP, no models simultaneously include these two concepts. High correlation between these constructs often is a methodical problem but not to an extent that would overshadow the results. For example, a similar correlation $(\mathrm{r}=0.65)$ between PACAP and RACAP was in the research of Cepeda-Carrion et al. (2012) where measurements were based on the same source (Jansen et al., 2005). However, in SEM models, these variables often existed as separate constructs (e.g., Moos et al., 2013). In this research, we accounted for both sub-constructs of ACAP as enablers of innovativeness. Using hierarchical moderated multiple regression method, we analyzed both dimensions separately and avoid potential multicollinearity between PACAP and RACAP.

Table 1. Descriptive statistics

\begin{tabular}{|c|c|c|c|c|c|c|c|c|c|c|c|c|c|}
\hline & Variable & Mean & SD & 1 & 2 & 3 & 4 & 5 & 6 & 7 & 8 & 9 & 10 \\
\hline 1. & Employees & 3.20 & 1.78 & & & & & & & & & & \\
\hline 2. & Industry & 10.67 & 4.38 & $0.17^{*}$ & & & & & & & & & \\
\hline 3. & Ownership & 1.94 & 1.32 & $0.51^{* *}$ & 0.07 & & & & & & & & \\
\hline 4. & Age & 30.72 & 28.44 & $0.60^{* *}$ & $0.15^{*}$ & $0.33^{* *}$ & & & & & & & \\
\hline 5. & PACAP & 4.77 & 1.36 & $0.41^{* *}$ & $0.14^{*}$ & $0.32^{* *}$ & $0.24^{* *}$ & & & & & & \\
\hline 6. & RACAP & 4.57 & 1.13 & 0.03 & $0.26^{* *}$ & 0.01 & 0.02 & $0.64 * *$ & & & & & \\
\hline 7. & COGCQ & 4.28 & 1.07 & 0.04 & -0.06 & $0.23^{* *}$ & 0.07 & $0.48 * *$ & $0.32 * *$ & & & & \\
\hline 8. & METCQ & 5.71 & 1.14 & $0.14^{*}$ & $0.20^{* *}$ & $0.28^{* *}$ & 0.09 & $0.43 * *$ & $0.35^{* *}$ & $0.47 * *$ & & & \\
\hline 9. & MOTCQ & 4.98 & 1.09 & $0.14 *$ & 0.05 & $0.25^{* *}$ & 0.08 & $0.48^{* *}$ & $0.46^{* *}$ & $0.41^{* *}$ & $0.58^{* *}$ & & \\
\hline 10. & BEHCQ & 4.42 & 1.08 & -0.21 & -0.08 & -0.02 & 0.08 & 0.11 & $0.16^{*}$ & $0.30^{* *}$ & $0.48^{* *}$ & $0.45^{* *}$ & \\
\hline 11. & INV & 4.43 & 1.42 & $0.25^{* *}$ & $0.31 * *$ & $0.23^{* *}$ & 0.06 & $0.49^{* *}$ & $0.66^{* *}$ & $0.18^{* *}$ & $0.32 * *$ & $0.27 * *$ & $-0,03$ \\
\hline
\end{tabular}

${ }^{*} \mathrm{p}<0.05,{ }^{* * \mathrm{p}}<0.01 . \mathrm{N}=215$. 
To examine the issue of multicollinearity in our models, we calculated variance inflation factors [VIFs] in each of the regression equations. The maximum VIF within the models was 2.52. This suggests that multicollinearity is not an important concern in the tested models. Table 2 presents the hypothesized results of main interaction effects. For all the regressions, we report robust standard error to address the heteroscedasticity (White, 1980).

Model 1 is the baseline model with all control variables included. Model 2 and 4 includes main effects put forward in Hypotheses 1 and 2. Model 3 and 5 includes the interaction terms needed to test hypotheses 3 and 4. Corroborating Hypothesis 1, the effect of PACAP on firm innovativeness is found to be significant and positive $(\beta=0.44, \mathrm{p}<0.001)$ as shown in Model 2. The results of Model 4 strongly supports Hypothesis 2, which proposes a positive impact of RACAP on innovativeness $(\beta=0.85, \mathrm{p}<0.001)$. Compared with the baseline model, Model 2 and 4 explain a significantly greater variance of the firm innovativeness (respectively $\Delta \mathrm{R}^{2}=0.16, \mathrm{p}<0.001$ and $\Delta \mathrm{R}^{2}=0.38, \mathrm{p}<0.001$ ).

Hypothesis 3 proposes that metacognitive (a), cognitive (b), motivational (c), and behavioral (d) intelligence dimensions of CQ positively moderate the link between PACAP and innovativeness. In model 3, the interaction terms between PACAP and metacognitive intelligence $(\beta=0.18, p<0.01)$ and behavioral intelligence $(\beta=0.17, \mathrm{p}<0.01)$ are both positive and statistically significant. The interaction terms between PACAP and cognitive intelligence $(\beta=0.10, \mathrm{p}>0.05)$ and motivational intelligence $(\beta=0.02, \mathrm{p}>0.05)$ are not statistically significant. However, compared with Model 2, Model 3 explains a greater amount of variance in firm innovativeness $\left(\Delta R^{2}=0.05, p<0.01\right)$. Hence, moderation effect of CQ in the link between PACAP and innovativeness was partially approved. Hypotheses $3 \mathrm{a}$ and $3 \mathrm{~d}$ are supported, but Hypotheses $3 \mathrm{~b}$ and $3 \mathrm{c}$ are not supported.

Hypothesis 4 proposes that metacognitive (a), cognitive (b), motivational (c), and behavioral (d) intelligence dimensions of CQ positively moderate the link between RACAP and innovativeness. In model 5 the interaction terms between RACAP and metacognitive intelligence $(\beta=0.16, p<0.05)$ is positive and statistically significant. However, the interaction terms between RACAP and others 
dimensions of CQ are not statistically significant. Moreover, compared with Model 4, Model 5 does not explain a significantly greater variance of firm innovativeness $\left(\Delta R^{2}=0.01, p>0.05\right)$. Hence, Hypothesis 4 is not supported, which shows that the link between RACAP and firm innovativeness is independent of CQ.

Table 2. The moderating role of CQ: Hierarchical regression analysis results

\begin{tabular}{|c|c|c|c|c|c|}
\hline & & & $\mathbf{Y}=\mathbf{I N V}$ & & \\
\hline & Model1 & Model2 & Model3 & Model4 & Model5 \\
\hline \multicolumn{6}{|l|}{ Control variables } \\
\hline Industry & $\begin{array}{c}0.09 * * * \\
(0.21)\end{array}$ & $\begin{array}{c}0.07 * * * \\
(0.02)\end{array}$ & $\begin{array}{c}0.06^{* *} \\
(0.02)\end{array}$ & $\begin{array}{c}0.02 \\
(0.02)\end{array}$ & $\begin{array}{c}0.02 \\
(0.02)\end{array}$ \\
\hline Employment size & $\begin{array}{c}0.171^{*} \\
(0.26)\end{array}$ & $\begin{array}{c}0.05 \\
(0.07)\end{array}$ & $\begin{array}{c}0.09 \\
(0.07)\end{array}$ & $\begin{array}{c}0.15^{* *} \\
(0.05)\end{array}$ & $\begin{array}{c}0.17^{* *} \\
(0.02)\end{array}$ \\
\hline Firm's age & $\begin{array}{l}-0.01 * \\
(0.004)\end{array}$ & $\begin{array}{c}-0.01 \\
(0,004)\end{array}$ & $\begin{array}{c}-0.01^{\mathrm{a}} \\
(0.004)\end{array}$ & $\begin{array}{c}-0.01 \\
(0,003)\end{array}$ & $\begin{array}{l}-0.01^{*} \\
(0.003)\end{array}$ \\
\hline Ownership & $\begin{array}{l}0.16^{*} \\
(0.08)\end{array}$ & $\begin{array}{c}0.07 \\
(0.07)\end{array}$ & $\begin{array}{c}0.08 \\
(0.07)\end{array}$ & $\begin{array}{c}0.17 * * \\
(0.06)\end{array}$ & $\begin{array}{c}0.18 * * \\
(0.06)\end{array}$ \\
\hline \multicolumn{6}{|l|}{ Main effects } \\
\hline PACAP & & $\begin{array}{c}0.44^{* * *} \\
(0.08)\end{array}$ & $\begin{array}{c}0,44 * * * \\
(0.08)\end{array}$ & & \\
\hline RACAP & & & & $\begin{array}{c}0.85^{* * *} \\
(0.07)\end{array}$ & $\begin{array}{c}0.82 * * * \\
(0.07)\end{array}$ \\
\hline MCQ & & $\begin{array}{c}0.15 \\
(0.10)\end{array}$ & $\begin{array}{c}0.11 \\
(0.12)\end{array}$ & $\begin{array}{l}0.16^{\mathrm{a}} \\
(0.8)\end{array}$ & $\begin{array}{c}0.09 \\
(0.09)\end{array}$ \\
\hline CCQ & & $\begin{array}{l}-0,09 \\
(0.10)\end{array}$ & $\begin{array}{l}-0.11 \\
(0.10)\end{array}$ & $\begin{array}{l}-0.09 \\
(0.07)\end{array}$ & $\begin{array}{l}-0.12 \\
(0.08)\end{array}$ \\
\hline MOCQ & & $\begin{array}{c}0.03 \\
(0.09)\end{array}$ & $\begin{array}{c}0.04 \\
(0.09)\end{array}$ & $\begin{array}{l}-0.16^{\mathrm{a}} \\
(0.08)\end{array}$ & $\begin{array}{l}-0.13 \\
(0.08)\end{array}$ \\
\hline BCQ & & $\begin{array}{l}-0.06 \\
(0.08)\end{array}$ & $\begin{array}{l}-0,13 \\
(0.08)\end{array}$ & $\begin{array}{l}-0.07 \\
(0.07)\end{array}$ & $\begin{array}{l}-0.09 \\
(0.07)\end{array}$ \\
\hline \multicolumn{6}{|l|}{ Interaction effects } \\
\hline PACAPXMCQ & & & $\begin{array}{c}0.18 * * \\
(0.06)\end{array}$ & & \\
\hline PACAPXCCQ & & & $\begin{array}{c}0.10 \\
(0.06)\end{array}$ & & \\
\hline PACAPXMOCQ & & & $\begin{array}{c}0.02 \\
(0.06)\end{array}$ & & \\
\hline PACAPXBCQ & & & $\begin{array}{c}0.17 * * \\
(0.06)\end{array}$ & & \\
\hline RACAPXMCQ & & & & & $\begin{array}{l}0.16^{*} \\
(0.06)\end{array}$ \\
\hline RACAPXCCQ & & & & & $\begin{array}{c}0.07 \\
(0.07)\end{array}$ \\
\hline RACAPXMOCQ & & & & & $\begin{array}{c}0.04 \\
(0.06)\end{array}$ \\
\hline RACAPxBCQ & & & & & $\begin{array}{c}0.08 \\
(0.06)\end{array}$ \\
\hline Constant & $\begin{array}{c}2.82 * * * \\
(0.27)\end{array}$ & $\begin{array}{c}3.57 * * * \\
(0.28)\end{array}$ & $\begin{array}{c}3.63 * * * \\
(0.29)\end{array}$ & $\begin{array}{c}3.54 * * * \\
(0.22)\end{array}$ & $\begin{array}{c}3.61 * * * \\
(0.23)\end{array}$ \\
\hline $\mathbf{R}^{2}$ & 0.167 & 0.331 & 0.379 & 0.741 & 0.562 \\
\hline Adjusted R R $^{2}$ & 0.151 & 0.301 & 0.339 & 0.530 & 0.534 \\
\hline$\Delta \mathbf{R}^{2}$ & & 0.164 & 0.048 & 0.383 & 0.012 \\
\hline
\end{tabular}




\begin{tabular}{|c|c|c|c|c|c|}
\hline F-statistics & $10.50 * * *$ & $11.26^{* * *}$ & $9.44^{* * *}$ & $27.78 * * *$ & $19.83^{* * *}$ \\
\hline Hierarchical F & & $10.05^{* * *}$ & $3.91 * *$ & $34.83 * * *$ & 1.43 \\
\hline
\end{tabular}

${ }^{\mathrm{a}} \mathrm{p}<0.1,{ }^{*} \mathrm{p}<0.05,{ }^{* * \mathrm{p}}<0.01,{ }^{* * *} \mathrm{p}<0.001$.

Notes: (1) Unstandardized coefficients, (2) Standard errors in parentheses

\section{Discussion and conclusion}

In this study, we explored the nexus of relationships between CQ, PACAP, RACAP, and innovativeness. CQ, the concept in which the study's main contribution resides, is viewed as a dynamic capability (Moon, 2010) that can contribute to firm innovativeness. The central thesis of this research is that firms may improve two-way communications and maintain more effective and closer cooperation with their partners that can spur creation and deployment of innovative ideas as a result of cultural acumen and sensitivity, proper behavior, and adaptation capability.

\subsection{Theoretical contributions}

We highlight that CQ can be one of the potential contingent concepts to the link between absorptive capacity and innovation. By complying with seminal research dividing absorptive capacity into two distinct yet complementary concepts of PACAP and RACAP (Jansen et al., 2005; Zahra \& George, 2002), we show that CQ moderates only the influence of PACAP on innovativeness. In particular, our findings imply that it is the control of cognition and manifestation of CQ that really matters for transforming PACAP into innovative capability. In other words, the planning, monitoring, and revision of mental models about cultural capabilities and manifesting CQ in practice can foster PACAP's role in innovativeness.

The utility of ACAP relies on finding and initiating relationships in business networks with the right type of connections and making the best use of diverse knowledge and insights from such ties for innovative purposes (Borgatti \& Foster, 2003; Dyer \& Singh, 1998). A cultural capability that enables successfully navigating in unfamiliar waters and not only tolerating but in fact leveraging diversity (Ang et al., 2007; Moon, 2010) for innovation could be a proper catalyst for exploring and acquiring external knowledge. Our findings highlight that CQ could foster spanning boundaries toward diverse and unfamiliar ties that are more likely to be a novel and unconventional source of 
knowledge and innovation (Borgatti \& Foster, 2003). Accordingly, our research highlights the need for further understanding of the role of capabilities that enable transcending survival levels of crosscultural understanding and intercultural communication in diverse and ambiguous settings so as to fully appreciate behavioral underpinnings of innovativeness. In doing so, it paves the way for and promotes the application of CQ to relevant issues in innovation strategy.

On the other hand, as none of the CQ's dimensions appear to influence RACAP's role in innovativeness, it may be feasible to argue that CQ matters more to the application of potential rather than realized knowledge management capabilities leading to innovativeness. RACAP mainly involves internal processing and appropriation of already explored and acquired external knowledge. $\mathrm{CQ}$, by its nature, is relatively more relevant for the firm's external, rather than internal, environments where cultural diversity and ambiguity is often more pronounced. Thus, the lack of moderation by CQ to the link between RACAP and innovativeness is not in contradiction to the core premise of CQ that favors exploration, heterogeneity, and unpredictability over exploitation, homogeneity, and certainty (Elenkov \& Manev, 2009; Moon, 2010).

\subsection{Managerial implications}

Our findings speak to managers who want to improve their firm's innovativeness. We find that CQ is a relevant catalyst for innovation. Our findings confirm the importance of CQ as a noteworthy enabler of exploring knowledge and idea resources for innovativeness. Thus, organizational-level CQ should be developed by promoting intercultural awareness and skills of employees in an orchestrated manner across the firm. In particular, managers are advised to foster metacognitive and behavioral underpinnings of CQ in their organizational environments to translate their PACAP effectively into innovative capabilities. Such pursuit requires creating and maintaining an organizational climate that empowers employees to develop knowledge and control of their cognition that fosters sensitivity to their external environment and to adopt practices and habits that enable effective intercultural interactions. 
In a similar vein, in line with our findings, we advise firms to deploy CQ when initiating and managing relationships with various network ties in order to facilitate exploration of new idea and knowledge resources for innovation. The firm-wide diffusion of cognitive abilities and practices underlying effective intercultural exchanges is likely to increase the chances of reaping benefits of knowledge exploration for innovation. Thus, managers should take soft aspects of intercultural relations seriously, if they want to make the best use of knowledge exploration for innovativeness. 
Appendix: Measurement items and validity assessment CFA results: $\chi 2 / \mathrm{df}=1.98, \mathrm{RMSA}=0.068, \mathrm{CFI}=0.95$

\begin{tabular}{|c|c|c|}
\hline Items & Loadings & Cronbach's $\alpha$ \\
\hline Firm innovativeness (7-point Likert) (Golgeci \& Ponomarov, 2013) & & 0.85 \\
\hline \multicolumn{3}{|l|}{$\mathrm{AVE}=0.62, \mathrm{CR}=0.89$} \\
\hline $\begin{array}{l}\text { 1. Our firm's management actively seeks innovative technologies, processes, techniques, and/or } \\
\text { product ideas }\end{array}$ & 0.87 & \\
\hline 2. Innovation in our firm is perceived as too risky and is resisted (R) (Hurley and Hult 1998) & 0.70 & \\
\hline 3. Our firm is known as an innovator among firms in our area. & 0.80 & \\
\hline 4. Our firm investigates and secures funds needed to implement new ideas & 0.72 & \\
\hline 5. Our firm constantly experiments with new ideas. & 0.84 & \\
\hline Potential Absorptive Capacity, (Jansen, et al., 2005) & & 0.90 \\
\hline \multicolumn{3}{|l|}{$\mathrm{AVE}=0.60 . \mathrm{CR}=0.90$} \\
\hline $\begin{array}{l}\text { 1. We collect industry information through informal means (e.g., lunch with industry friends, talks } \\
\text { with trade partners). }\end{array}$ & 0.85 & \\
\hline $\begin{array}{l}\text { 2. My firm periodically organizes special meetings with customers or third parties to acquire new } \\
\text { knowledge. }\end{array}$ & 0.84 & \\
\hline $\begin{array}{l}\text { 3. We allocate a lot of time to the establishment of contact with parties who can provide us with } \\
\text { knowledge and information about innovations in the sector }\end{array}$ & 0.75 & \\
\hline $\begin{array}{l}\text { 4. We have sufficient skills to establish contact with parties who can provide us with knowledge and } \\
\text { information about innovations in the sector. }\end{array}$ & 0.78 & \\
\hline 5. Employees regularly approach third parties such as accountants, consultants, or tax consultants. & 0.71 & \\
\hline 6. We quickly analyze and interpret changing market demands. & 0.70 & \\
\hline Realized Absorptive Capacity (Jansen, et al., 2005) & & 0.90 \\
\hline \multicolumn{3}{|l|}{$\mathrm{AVE}=0.57, \mathrm{CR}=0.87$} \\
\hline 1. Our firm quickly recognizes the usefulness of new external knowledge to existing knowledge. & 0.70 & \\
\hline $\begin{array}{l}\text { 2. We laboriously grasp the opportunities for our firm from new external knowledge. (reverse- } \\
\text { coded) }\end{array}$ & 0.75 & \\
\hline 3. Client complaints fall on deaf ears in our unit. (reverse-coded) & 0.79 & \\
\hline 4. We constantly consider how to better exploiting knowledge & 0.73 & \\
\hline 5. Employees have a common language regarding our products and services & 0.80 & \\
\hline Metacognitive Intelligence, (Ang, et al., 2007) & & 0.87 \\
\hline \multicolumn{3}{|l|}{$\mathrm{AVE}=\mathbf{0 . 6 8}, \mathrm{CR}=\mathbf{0 . 8 6}$} \\
\hline $\begin{array}{l}\text { 1. I am conscious of the cultural knowledge I use when interacting with people with different cultural } \\
\text { backgrounds. }\end{array}$ & 0.86 & \\
\hline 2. I adjust my cultural knowledge as I interact with people from a culture that is unfamiliar to me. & 0.73 & \\
\hline 3. I am conscious of the cultural knowledge I apply to cross-cultural interactions. & 0.88 & \\
\hline Cognitive Intelligence, (Ang, et al, 2007) & & 0.87 \\
\hline \multicolumn{3}{|l|}{$\mathrm{AVE}=0.52, \mathrm{CR}=0.81$} \\
\hline 1. I know the legal and economic systems of other cultures. & 0.65 & \\
\hline 2. I know the rules (e.g., vocabulary, grammar) of other languages. & 0.71 & \\
\hline 3. I know the cultural values and religious beliefs of other cultures. & 0.77 & \\
\hline 4. I know the rules for expressing nonverbal behaviors in other cultures & 0.76 & \\
\hline Motivational Intelligence, (Ang, et al., 2007) & & 0.81 \\
\hline \multicolumn{3}{|l|}{$\mathrm{AVE}=0.65, \mathrm{CR}=0.85$} \\
\hline 1. I am confident that I can socialize with locals in a culture that is unfamiliar to me. & 0.84 & \\
\hline 2. I am sure I can deal with the stresses of adjusting to a culture that is new to me. & 0.83 & \\
\hline 3. I am confident that I can get accustomed to the shopping conditions in a different culture. & 0.75 & \\
\hline Behavioral Intelligence, (Ang, et al., 2007) & & 0.77 \\
\hline \multicolumn{3}{|l|}{$\mathrm{AVE}=0.65, \mathrm{CR}=0.85$} \\
\hline 1. I change my verbal behavior (e.g., accent, tone) when a cross-cultural interaction requires it. & 0.74 & \\
\hline 2. I vary the rate of my speaking when a cross-cultural situation requires it. & 0.87 & \\
\hline 3. I alter my facial expressions when a cross-cultural interaction requires it. & 0.80 & \\
\hline
\end{tabular}




\section{References}

Ang, S., \& Inkpen, A. C. (2008). Cultural Intelligence and Offshore Outsourcing Success: A Framework of Firm-Level Intercultural Capability. Decision Sciences, 39: 337-358.

Ang, S., Van Dyne, L., \& Koh, C. (2006). Personality Correlates of the Four-Factor Model of Cultural Intelligence. Group \& Organization Management, 31: 100-123.

Ang, S., Van Dyne, L., Koh, C., Ng, K. Y., Templer, K. J., Tay, C., \& Chandrasekar, N. A. (2007). Cultural Intelligence: Its Measurement and Effects on Cultural Judgment and Decision Making, Cultural Adaptation and Task Performance. Management and Organization Review, 3: 335-371.

Azadegan, A., \& Dooley, K. J. (2010). Supplier Innovativeness, Organizational Learning Styles and Manufacturer Performance: An Empirical Assessment. Journal of Operations Management, 28 : 488-505.

Bagozzi, R. P., \& Yi, Y. (1988). On the Evaluation of Structural Equation Models. Journal of the Academy of Marketing Science, 16: 74-94.

Barreto, I. (2010). Dynamic Capabilities: A Review of Past Research and an Agenda for the Future. Journal of Management, 36: 256-280.

Borgatti, S. P., \& Foster, P. C. (2003). The Network Paradigm in Organizational Research: A Review and Typology. Journal of Management, 29: 991-1013.

Buckley, P. J. (2009). The Impact of the Global Factory on Economic Development. Journal of World Business, 44: 131-143.

Capaldo, A. (2007). Network Structure and Innovation: The Leveraging of a Dual Network as a Distinctive Relational Capability. Strategic Management Journal, 28: 585-608.

Carte, T. A., \& Russell, C. J. (2003). In Pursuit of Moderation: Nine Common Errors and Their Solutions. MIS Quarterly, 27: 479-501.

Cepeda-Carrion, G., Cegarra-Navarro, J. G., \& Jimenez-Jimenez, D. (2012). The Effect of Absorptive Capacity on Innovativeness: Context and Information Systems Capability as Catalysts. British Journal of Management, 23: 110-129.

Chang, S., Gong, Y., Way, S. A., \& Jia, L. (2013). Flexibility-Oriented Hrm Systems, Absorptive Capacity, and Market Responsiveness and Firm Innovativeness. Journal of Management, 39: 1924-1951.

Chen, X.-P., Liu, D., \& Portnoy, R. (2012). A Multilevel Investigation of Motivational Cultural Intelligence, Organizational Diversity Climate, and Cultural Sales: Evidence from Us Real Estate Firms. Journal of Applied Psychology, 97: 93-106.

Chin, W. W. (2003). Issues and Opinions on Structural Equation Modeling. MIS Quarterly, 22: 7-16.

Cohen, W. M., \& Levinthal, D. A. (1990). Absorptive Capacity: A New Perspective on Learning and Innovation. Administrative Science Quarterly, 35: 128-152.

Crocker, L., \& Algina, J. (1986). Introduction to Classical and Modern Test Theory. Fort Worth, TX: Harcourt College Publishers.

Dillman, D. A. (2007). Mail and Internet Surveys: The Tailored Design Method: John Wiley \& Sons Inc.

Dyer, J. H., \& Singh, H. (1998). The Relational View: Cooperative Strategy and Sources of Interorganizational Competitive Advantage. Academy of Management Review, 23: 660-679.

Earley, P. C., \& Ang, S. A. (2003). Cultural Intelligence: Individual Interactions across Cultures. Stanford. CA: Stanford business books.

Elenkov, D. S., \& Manev, I. M. (2009). Senior Expatriate Leadership's Effects on Innovation and the Role of Cultural Intelligence. Journal of World Business, 44: 357-369.

Fabrizi, A., Guarini, G., \& Meliciani, V. (2016). Public Knowledge Partnerships in European Research Projects and Knowledge Creation across R\&D Institutional Sectors. Technology Analysis \& Strategic Management1-17.

Fornell, C., \& Larcker, D. F. (1981). Evaluating Structural Equation Models with Unobservable Variables and Measurement Error. Journal of marketing Research, 18: 39-50.

Golgeci, I., \& Ponomarov, S. Y. (2013). Does Firm Innovativeness Enable Effective Responses to Supply Chain Disruptions? An Empirical Study. Supply Chain Management: An International Journal, 18: 604-617. 
Gölgeci, I., \& Ponomarov, S. Y. (2015). How Does Firm Innovativeness Enable Supply Chain Resilience? The Moderating Role of Supply Uncertainty and Interdependence. Technology Analysis \& Strategic Management, 27: 267-282.

Hair, J. F., Black, W. C., Babin, B. J., \& Anderson, R. E. (2010). Multivariate Data Analysis - a Global Perspective (7th ed.). Upper Saddle River, NJ: Pearson Prentice Hall.

Hofstede, G. (1983). National Cultures in Four Dimensions: A Research-Based Theory of Cultural Differences among Nations. International Studies of Management \& Organization, 13: 46-74.

Imai, L., \& Gelfand, M. J. (2010). The Culturally Intelligent Negotiator: The Impact of Cultural Intelligence $(\mathrm{Cq})$ on Negotiation Sequences and Outcomes. Organizational behavior and human decision processes, 112: 83-98.

Jansen, J., Van Den Bosch, F., \& Volberda, H. W. (2005). Managing Potential and Realized Absorptive Capacity: How Do Organizational Antecedents Matter? Academy of Management Journal, 48: 999-1015.

Klafehn, J., Banerjee, P. M., \& Chiu, C. Y. (2009). Navigating Cultures: The Role of Metacognitive Cultural Intelligence. In S. Ang \& V. D. Dyne (Eds.), Handbook of Cultural Intelligence: Theory, Measurement, and Applications (pp. 318-331). Armonk, NY: M.E. Sharpe.

Lane, P. J., Koka, B. R., \& Pathak, S. (2006). The Reification of Absorptive Capacity: A Critical Review and Rejuvenation of the Construct. Academy of Management Review, 31: 833-863.

Leal-Rodríguez, A. L., Ariza-Montes, J. A., Roldán, J. L., \& Leal-Millán, A. G. (2014). Absorptive Capacity, Innovation and Cultural Barriers: A Conditional Mediation Model. Journal of Business Research, 67: 763-768.

Lichtenthaler, U., \& Lichtenthaler, E. (2009). A Capability-Based Framework for Open Innovation: Complementing Absorptive Capacity. Journal of Management Studies, 46: 1315-1338.

Magnusson, P., Westjohn, S. A., Semenov, A. V., Randrianasolo, A. A., \& Zdravkovic, S. (2013). The Role of Cultural Intelligence in Marketing Adaptation and Export Performance. Journal of International Marketing, 21: 44-61.

Mckenna, S. P., Wilburn, J., Thorsen, H., \& Brodersen, J. (2013). Adapting Patient-Reported Outcome Measures for Use in New Languages and Cultures. In K. B. Christensen, S. Kreiner, \& M. Mesbah (Eds.), Rasch Models in Health (pp. 303-316). Hoboken, NJ USA: John Wiley \& Sons, Inc.

Molinsky, A. (2007). Cross-Cultural Code-Switching: The Psychological Challenges of Adapting Behavior in Foreign Cultural Interactions. Academy of Management Review, 32: 622-640.

Moon, T. (2010). Organizational Cultural Intelligence: Dynamic Capability Perspective. Group \& Organization Management, 35: 456-493.

Moos, B., Beimborn, D., Wagner, H.-T., \& Weitzel, T. (2013). The Role of Knowledge Management Systems for Innovation: An Absorptive Capacity Perspective. International Journal of Innovation Management, 17: 1350019.

Nunnally, J. C., \& Bernstein, I. H. (1994). Psychometric Theory. New York, NY: McGraw-Hill.

Renko, A.-M. (2008). The Role of Market Knowledge in Recognizing and Exploiting Entrepreneurial Opportunities in Technology Intensive Firms. (FIU Electronic Theses and Dissertations), Florida International University, Miami, FL. Retrieved from http://digitalcommons.fiu.edu/etd/38

Schwab, K., Sala-i-Martin, X., \& Brende, B. (2013). The Global Competitiveness Report 2013-2014 (9295044258). Retrieved from

Schwartz, S. H. (2006). A Theory of Cultural Value Orientations: Explication and Applications. Comparative Sociology, 5: 137-182.

Shapiro, J. M., Ozanne, J. L., \& Saatcioglu, B. (2007). An Interpretive Examination of the Development of Cultural Sensitivity in International Business. Journal of International Business Studies, 39: $1-17$.

Sultan, N., \& van de Bunt-Kokhuis, S. (2012). Organisational Culture and Cloud Computing: Coping with a Disruptive Innovation. Technology Analysis \& Strategic Management, 24: 167-179.

Taras, V., Kirkman, B. L., \& Steel, P. (2010). Examining the Impact of Culture's Consequences: A Three-Decade, Multilevel, Meta-Analytic Review of Hofstede's Cultural Value Dimensions. Journal of Applied Psychology, 95: 405-439. 
Teece, D. J. (2009). Dynamic Capabilities and Strategic Management: Organizing for Innovation and Growth. New York, NY: Oxford University Press.

Todorova, G., \& Durisin, B. (2007). Absorptive Capacity: Valuing a Reconceptualization. Academy of Management Review, 32: 774-786.

Tuominen, M., Rajala, A., \& Möller, K. (2004). How Does Adaptability Drive Firm Innovativeness? Journal of Business Research, 57: 495-506.

Van Everdingen, Y. M., \& Waarts, E. (2003). The Effect of National Culture on the Adoption of Innovations. Marketing Letters, 14: 217-232.

Volberda, H. W., Foss, N. J., \& Lyles, M. A. (2009). Absorbing the Concept of Absorptive Capacity: How to Realize Its Potential in the Organization Field. Organization Science, 20: 352-367.

White, H. (1980). A Heteroskedasticity-Consistent Covariance Matrix Estimator and a Direct Test for Heteroskedasticity. Econometrica, 48: 817-838.

Yu, Y., Dong, X.-Y., Shen, K. N., Khalifa, M., \& Hao, J.-X. (2013). Strategies, Technologies, and Organizational Learning for Developing Organizational Innovativeness in Emerging Economies. Journal of Business Research, 66: 2507-2514.

Zahra, S. A., \& George, G. (2002). Absorptive Capacity: A Review, Reconceptualization, and Extension. Academy of Management Review, 27: 185-203. 